\title{
Comparing Online Social Networks Ties as Tool for Entrepreneurial Learning Readiness in Small Economies
}

\author{
Oliana SULA, Tiit ELENURM \\ Estonian Business School, Tallinn, Estonia \\ olasula@hotmail.com.ar, tiit.elenurm@ebs.ee
}

Online social networks such as Facebook and LinkedIn create the opportunity to expand online and face-to-face ties. Diverse online social network composed by weak and strong ties is essential for the young student entrepreneurs. Online networks off diverse learning and online expertize opportunities to the young student entrepreneur. This paper explores the entrepreneurial learning leverage that young students enrolled in higher education system can get from online ties in small economies through comparing Western Balkan region and more precisely a small developing country such as Albania with a small-developed county such as Estonia. The paper explores how online ties support young student readiness to use online networking platforms for online entrepreneurial learning and entrepreneurial opportunity recognition focusing in online ties established in Facebook and LinkedIn. Further online learning strategies are explored through focus group analysis, blog analysis and interviews with young experienced entrepreneurs. Young students use online ties for entrepreneurial knowledge sharing but there a difference between the Facebook tie and the LinkedIn tie. The study concludes with the suggestion of development of entrepreneurial learning orientation strategies and tools that facilitate the online learning process in both online networks focusing in specific online tie that is the group tie.

Keywords: Online Entrepreneurial Ties, Online Entrepreneurial Learning, Online Knowledge Sharing, Facebook Ties, LinkedIn Ties, Group Ties

1 Introduction

Young students enrolled in higher education institutions in developed and developing countries use online social networks such as Facebook and LinkedIn for professional and personal development creating and maintaining business relationships of young potential entrepreneurs. Facebook tie and LinkedIn tie emerges as a new kind of ties different from the offline ties because the relationship is maintained virtually with cross-border perspective.

Online entrepreneurial networking is essential because it provides cross-border entrepreneurial opportunities and online entrepreneurial learning opportunities. Online social networks such as Facebook and LinkedIn give the possibility to develop online ties useful for the young student entrepreneurs that are familiar with features of online social networks. For young students which are very familiar with online social networking $\mathrm{T}$ Young students however need to assess how to relate and rely to online social networking ties to online networking tools that support discovering crossborder entrepreneurial opportunities and knowledge that is relevant for entrepreneurial initiatives.

Global Entrepreneurship Monitor (GEM) 2012-2014 Estonian surveys have demonstrated the role of cross-border ties in developing ambitious internationally oriented entrepreneurial initiatives but also networking needs of early-stage entrepreneurs. Entrepreneurs with an international innovative have often relied on knowledge sharing with international contact while entrepreneurs that were domestically focused use stronger ties such as relatives and friends [1].

In Albania, online social networks are accessible from young students like in every part of the world. However awareness and implementation perspectives for integrating them in the entrepreneurial learning process and entrepreneurial opportunity hunting are lacking. The aim of this paper is to explore how to online 
ties $\mathrm{c}$ in the context of online social networks can support contribute to online entrepreneurial learning readiness for young students in small transition economy such as Albania, compared with a more developed economy such as Estonia focusing on the comparisons between two principal online networks Facebook and LinkedIn. An exploratory study with young students from University "Aleksander Moisiu" Durres in Albania and Estonian Business School in Tallinn Estonia is presented.

A questionnaire was distributed to 130 young students in both countries during spring semester of the academic year 2016/2017, focus groups were applied in Albania and in Estonia during spring semester 2018 of the academic year 2016/ 2017 and the posts of the blog of the course Business in Virtual Networks at Estonian Business School were analyzed for the year 2016 and 2017. Interviews were realized with more experienced Albanian and Estonian young entrepreneurs during July 2018 ,

In the second section of the paper theoretical constructs are explored, research gaps are identified theoretical gaps in terms of online ties, online and entrepreneurial learning. Methodology and data analysis results are presented respectively in the third and fourth section, results are analyzed in the fifth section concluding in the sixth section with discussion and conclusions.

\section{Literature Review}

\subsection{Online ties as online learning ties for youth entrepreneurship}

Face-to-face social networks are characterized by diverse network ties, which are a main feature of network structure. Face-to-face ties influence business development and entrepreneurial learning of young students because entrepreneurship is a situational exchange of knowledge [2] and the relational dimension of face-to-face ties influence business development [3].

Strength of a tie depends intensity of interaction and the diversity of relationships or the amount of time that young students spend in creating such a tie [4].There are two main categories of face-to-face ties: weak ties and strong ties. Strong ties usually refer to closer social interaction such as friends and family with whom there is closer emotional interaction and contact, [5]. The role of weak ties is especially important in knowledge diverse environments [6].In online social networks weak ties are created in a virtual context without having contextual references of time and space [7]. That may be essential for earlystage cross-border knowledge sharing and business initiatives of young students.

Online networks are particularly important for small and medium enterprises and young entrepreneurs as they provide a unique opportunity to access business related information and knowledge sources at different stages of the entrepreneurial project [8]. Some of the benefits of using online social networks are cost, knowledge sharing and creation of the virtual teams [9].

Developing both weak and strong ties for young entrepreneurs is essential because as simplistic as it can be networking for and entrepreneur means basically increasing the " business friends" circle through their get from the current "friends" or contacts in order to advance in their business and achieve desirable results. The more diversified is the network in terms of ties and particularity in terms of quality of ties the more beneficial it will be for the young entrepreneur rather than a less developed network [10]. Although only certain young entrepreneurs can recognize innovative and cross-border entrepreneurial opportunities and entrepreneurial learning opportunities. For some scholars as [11] strong ties are more beneficial for entrepreneurs from a point view of knowledge sharing because they imply trust but knowledge sharing opportunities for entrepreneurs can from other sources than family members or closer friends [12]. Stronger ties provide help to reduce the time spent in monitoring business opportunities. Strong ties are useful to entrepreneurs who face high degree of uncertainty and insecurity especially in developing countries or small transition economies because they provide protection. On the other hand, strong ties are vulnerable to external shocks [13].

The increasing use of internet intensified the 
virtual connection between people worldwide, in business entrepreneurs could benefit from larger business friend circles [14] Online social networks are as well one of the greatest consequences of the development of the internet, they provide an establishing, maintaining and mediating of relationships through online social media platforms that can be used for business purposes such as Facebook, Google+, LinkedIn or Instagram. [15] have pointed out found that Twitter users had the highest bridging social capital, followed by Instagram, Facebook, and Snapchat, while Snapchat users had the highest bonding social capital, followed by Facebook, Instagram, and Twitter. Bridging social capital can enhance discovering new business opportunities and concept whereas bonding ties may be needed at later stages of a new business initiative, when trust becomes essential for developing co-creative teamwork.

Online ties are related traditionally to virtual interaction, but they cannot be considered only as weak ties just because their virtual dimension as example LinkedIn second degree and third degree contacts are an opportunity to wider weak contacts for entrepreneurial purposes or in Facebook the contact that can emerge from "friends of friends" [16]. An online tie can be strong or weak depending on the intensity of interaction and diversity of relationships that they provide, an offline tie that is related to face-to-face interaction within the network can be as well weak or strong depending on the intensity of interaction and the diversity of relationships [17]. Experienced usually monitor online social networking platforms such as Facebook and LinkedIn for entrepreneurial opportunities. Another dimension that counts defining online ties as entrepreneurial learning ties that influence youth entrepreneurship is cultural context; perceptions around online social networks may vary in different cultures, in individualist societies weaker ties are supposed to persist, in collectivist societies stronger ties are supposed to dominate [18].

Entrepreneurial knowledge sharing and opportunities sharing is a main advantage that young students benefit from online ties.

\subsection{Entrepreneurial knowledge sharing and opportunities through online ties}

One of the most relevant dimensions of knowledge management for the young entrepreneur involved in online social networks is knowledge sharing in order to find and use business opportunities and as well collaborative orientation in sharing entrepreneurial opportunities in online social network platforms. Knowledge sharing is influenced by informal sharing context that includes personal relationships and networks [19]. Networking knowledge sharing is empathized through face-to-face meetings, informal communication and it influences the way that entrepreneurs cooperate and communicate.

The strength of ties can affect knowledge sharing; stronger ties would lead to interaction that is more frequent and would facilitate the process of knowledge sharing [20]. Sharing knowledge with weak ties would to an access of new and unique knowledge because weak ties provide information and knowledge that goes beyond the social circle [21] and even better opportunities from the young entrepreneur.

Online social networks are perceived as new emerging paradigm that can be integrated with entrepreneurship paradigm. Online social networking tools enable the entrepreneur to share knowledge and to get expertize in the virtual context and use appropriate skills that will facilitate online entrepreneurial learning process [22]. For the young students it is crucial to determine opportunity and knowledge sharing orientations in online social networks according to the different stages of its entrepreneurial projects and to the entrepreneurial orientation. The co-creative entrepreneur prefers to share opportunities in networks which allow access to open innovation, imitative entrepreneur prefers to share opportunities will closer strong face-to-face ties and individualist entrepreneur does not rely much on networks as possibility of opportunities sharing [23]. Entrepreneurial knowledge sharing and opportunity sharing process in online social networks in the context of higher education institution is associated with young student learning. 
2.3 Supporting online entrepreneurial learning with online ties

Online social networks through distance interactions allow the accumulation of content of the time, which creates a sort of collaborative knowledge networks.

Online social networks provide unique learning environments through better communication and collaboration [24]. Young students need to rely support non-formal learning approaches and non-traditional learning through integrating online networking tools and online networking ties support from online ties in their entrepreneurial learning processes [25]. Young students are born digital process information in different settings in online networking environments, they exhibit specific

Online social networks are used both to maintain existing contact and to create new contact, in terms of online ties, online social networks provide new ways to connect with digital natives who share their interest and their goals. Young students who rely only in strong ties for learning purposes will be deprived from knowledge and business opportunities that come from weaker ties that might be in online social networks. Recent research in learning in online social networks shows that in order to enable individuals to learn in the context of online social networks, relationships build within the online social network context and the online social network itself should topicbased and with simple ties relations [25]. Formal and non-formal education should enable young students to get to know entrepreneurial learning opportunities from online social networks as benefit of the quick digitalization process and it provides a new flexible way of learning that can be accommodated by the young entrepreneurs, online ties can be a learning intermediary.

\subsection{Youth entrepreneurship in online social} networks and culture: a contextual matter?

[26] analyze impact of culture on learning styles, high context culture tend to prefer a high degree of abstraction while learning and low context culture adopt a learning orientation influenced by concrete experimentation.
In individualist low context societies, individuals will tend to have fewer but long-term intimate friendships, in collectivist high context societies individuals tends to rely more on fewer friends and enjoy more long-term intimate friendships. In highly individualistic cultures, individuals believe that holding certain information will lead them to success and in collectivistic societies organizational success is attributed to sharing information openly [27].

Learning opportunities in entrepreneurship and entrepreneurial opportunity recognition especially for young students involved into higher education system taking into accounting the learning environment that online social networking platforms provide should enable online social network users for entrepreneurial purposes to have certain degree of cultural awareness [28].

There is not yet relevant literature in the field of online social networking about to extent online networking ties of young student involved into higher education influence online entrepreneurial learning and knowledge sharing, entrepreneurial opportunity recognition in the context of online social networks and to what extend the cultural context influences learning in the context of online social networks for young student entrepreneurs especially focusing on specific ties formed in particular business platforms.

\section{Methodology}

The aim of this exploratory research is to determine how online ties can support online entrepreneurial learning within the context of online social networks in small transition economies in Western Balkan Region in Europe such as Albania that can be classified as high context, collectivist society.

Online social networks can be an educational tool for entrepreneurial learning that can compensate traditional curricula offered formal higher education institutions. Entrepreneurial learning through online social networks is an unexplored phenomenon in the context of Albania but it can be a leverage for young students from online social networking. Online 
social networks can widen the learning opportunities and can make young students more connected especially in the context of small transition economies. Comparison can be made in order to share examples of best practices of the use of online social networks for entrepreneurial learning from Estonia, which is a small country in Europe but part of OECD and European Union with several achievements in terms of digitalization, digital policy, innovation and entrepreneurship policy.

In this study, mixed-methods are used. The sample of the study is composed by 130 young business students enrolled at the third year of Bachelor Degree and first and second year of Master Degree at the University "Alekander Moisiu" Durres and 43 young student enrolled at 2nd and 3rd year of Bachelor Degree in International Business at Estonian Business School, in Tallinn Estonia.

Triangulation is conducted through gathering primary data through the distribution of a survey to young business students in Durres and in Tallinn during the spring semester of the academic year 2016/2017. Four focus groups composed of young business students were realized in Durres during the spring semester of the academic year 2016/2017 and secondary data from the course Business in Virtual Networks which contains students posts dating from the year 2010 but for this study posts of the year 2016 and 2017 were taken into account, in total for this time period there are 130 post from students.

The questionnaire contains 24 questions that combine open-ended questions, Likert scale questions and closed questions. There are questions about online ties and entrepreneurial learning outcome from online social networks. Students were also asked to assess their online social networking priorities and their online social networking skills priorities. Survey serves just to identify the general trends; there was a need to study in-depth online social networking ties, online social network learning and online social network knowledge sharing through focus groups and posts of the blog of the course Business in Virtual Networks.

Focus groups in Durres were organized in
Spring 2017 and in Spring 2018 with three groups of eight students each from the $3 \mathrm{rd}$ year of Bachelor Degree in Business Administration and 2nd year of Master Degree in Business Administration based on the fact that Entrepreneurship and Small and Medium Business Management is part of the course curricula and on the fact if they had some kind of participation in informal events connected to youth student entrepreneurship such as Startup weekends, they were moderated by an external moderator other than the lecturer in order to not bias the process. were To be effective focus group questions were openended and they moved from general to more specific questions about online social network usage in general, entrepreneurial learning in general, the influence that online ties have in general for students and more specifically for entrepreneurial learning and how the cultural context accommodated knowledge sharing in online social networks.

Secondary data were collected from the posts of the blog of the course Business in Virtual Networks at Estonian Business School. Students posted and commented each other posts on the use of online social networks focus on a large amount of specific and specialized online social networks that does not include traditional online social networks with massive use such as Facebook, LinkedIn, Instagram or Google+, an emphasis is put on advantages and disadvantages of these networks for entrepreneurial purposes. 130 posts where analyzed.

\subsection{Data analysis}

The questionnaire was used to determine general trends or online networking orientation of young students in Albania and in Estonia, the leverage that this study gets from the questionnaire is a description of general trends in online social networking ties. General descriptive statistics are presented in order to identify trends.

Focus groups were recorded, transcribed and translated from Albanian into English, data were coded, codes were organized in themes and themes were organized in global wider 
themes. Same procedure was used for analyzing blog posts. There were identified 40 codes and 5 themes. Interviews with 8 experienced Albanian young entrepreneurs and 4 experienced Estonian young entrepreneurs were realized in July 2018 in order to further explore roles and nature of ties formed in particular online social networks defined by survey which were Facebook and LinkedIn.

\section{Results}

\subsection{Comparing results from survey}

Online ties versus Face-to-Face ties related to business opportunity recognition and knowledge sharing were compared based on questionnaire results. In Table 1, trends in using online social networks to find and discuss about business ideas of young Albanian students and young Estonian students are compared considering the fact if students in both countries will have intention to start their entrepreneurial project abroad. The scale of measurement in the survey was a five- point Likert scale where 1=strongly disagree, $2=$ disagree, $\quad 3=$ neutral, $\quad 4=$ agree and $5=$ strongly agree, mean is used to compare the two groups. As it is shown in the table, young students in both countries tend to rely equally to face-to-face ties and online ties. The most relevant face-to-face tie for Albanian students who want to start their entrepreneurial project abroad is students from other universities and mentors whereas for students in Estonia who want to start their project abroad the most relevant face-to-face tie mentors followed by friends. For Albanian students who do not want to start their entrepreneurial project abroad the strongest face-to-face tie is entrepreneurs followed by mentors and in Estonia close friends followed by entrepreneurs. Online social networks are perceived almost equally in both countries having a mean score that varies from 3.5-3.6 between neutral and agree. Table shows as well that family is a face-to-face tie that is not so preferred for entrepreneurial purposes by students in both countries. In Estonia, students will rely more experienced to their closest circle such as friends whereas in Albania students will rely more entrepreneurs. Mentors are an important face-to-face tie in both countries, there is no huge difference between online, and offline ties preferences.

Table 1. Comparison Online Ties vs Face-to-Face Ties for Young Albanian and Young Estonian students based on their willingness to start their entrepreneurial project abroad

\begin{tabular}{|l|c|c|c|c|}
\hline & \multicolumn{3}{|c|}{ Young Albanian Students } & \multicolumn{2}{l|}{ Young Estonian Students } \\
\hline $\begin{array}{l}\text { Online Ties vs Face- } \\
\text { to-Face Ties for En- } \\
\text { trepreneurial Read- } \\
\text { iness }\end{array}$ & $\begin{array}{l}\text { Willing to start } \\
\text { business abroad } \\
\text { 35 individuals }\end{array}$ & $\begin{array}{l}\text { Not willing to } \\
\text { start business } \\
\text { abroad } \\
\text { 57 individuals }\end{array}$ & $\begin{array}{l}\text { Willing to start } \\
\text { business } \\
\text { abroad } \\
\text { 16 individuals }\end{array}$ & $\begin{array}{l}\text { Not willing to } \\
\text { start business } \\
\text { abroad } \\
\text { 22 individuals }\end{array}$ \\
\hline Family & 3.7 & 3.3 & 3.7 & 3.4 \\
\hline Close Friends & 4 & 3.6 & 3.9 & 3.9 \\
\hline $\begin{array}{l}\text { Students in my uni- } \\
\text { versity }\end{array}$ & 3.5 & 3.2 & 3.7 & 3.8 \\
\hline $\begin{array}{l}\text { Students in other } \\
\text { universities }\end{array}$ & 4.4 & 3.3 & 3.2 & 3.5 \\
\hline Entrepreneurs & 4 & 4.3 & 3.7 & 4 \\
\hline Mentors & 3.8 & 4 & 4.2 & 3.9 \\
\hline E-mentors & 3 & 3.8 & 3 & 3 \\
\hline $\begin{array}{l}\text { Online Social Net- } \\
\text { works }\end{array}$ & 3.6 & 3.4 & 3.5 & 3.5 \\
\hline
\end{tabular}

In Table 2 Online Ties and Face-to-Face Ties are compared for Young Albanian Students and Young Estonian Students based on their previous entrepreneurial experience using 
means of the sample. As it is shown in Table 2 , there is not significant difference in terms of using networking ties for entrepreneurial purposes between those who already have entrepreneurial experience and those who do not have entrepreneurial experience. Young stu- dents tend to rely on mentors and entrepreneurs in both countries. Young Estonian Students who have already entrepreneurial experience use more than the other sub-groups in both countries online social networks as online entrepreneurial ties.

Table 2 Comparison Online Ties vs Face-to-Face Ties for Young Albanian and Young Estonian students based on their entrepreneurial experience

\begin{tabular}{|l|c|c|c|c|}
\hline & \multicolumn{2}{|c|}{ Young Albanian Students } & \multicolumn{2}{c|}{ Young Estonian Students } \\
\hline $\begin{array}{l}\text { Online Ties vs } \\
\text { Face-to-Face } \\
\begin{array}{l}\text { Ties for Entre- } \\
\text { preneurial Read- } \\
\text { iness }\end{array}\end{array}$ & $\begin{array}{l}\text { Entrepreneur- } \\
\text { ial Experience }\end{array}$ & $\begin{array}{l}\text { No Entrepreneur- } \\
\text { ial Experience } \\
\text { 82 individuals }\end{array}$ & $\begin{array}{l}\text { Entrepreneurial } \\
\text { Experience } \\
\mathbf{1 8} \text { individuals }\end{array}$ & $\begin{array}{l}\text { No Entrepre- } \\
\text { neurial Experi- } \\
\text { ence } \\
\text { 19 individuals }\end{array}$ \\
\hline Family & 4 & 3.4 & 3.5 & 3.4 \\
\hline Close Friends & 4.4 & 3.7 & 3.9 & 3.9 \\
\hline $\begin{array}{l}\text { Students in my } \\
\text { university }\end{array}$ & 3.5 & 3.7 & 3.7 & 3.9 \\
\hline $\begin{array}{l}\text { Students in other } \\
\text { universities }\end{array}$ & 3.4 & 3.4 & 3.3 & 3.5 \\
\hline Entrepreneurs & 4 & 4.5 & 4 & 3.9 \\
\hline Mentors & 4 & 4 & 4.1 & 3.9 \\
\hline E-mentors & 3.7 & 3.7 & 3 & 3.2 \\
\hline $\begin{array}{l}\text { Online Social } \\
\text { Networks }\end{array}$ & 3.5 & 3.4 & 3.8 & \\
\hline
\end{tabular}

Online networking priorities for business purposes

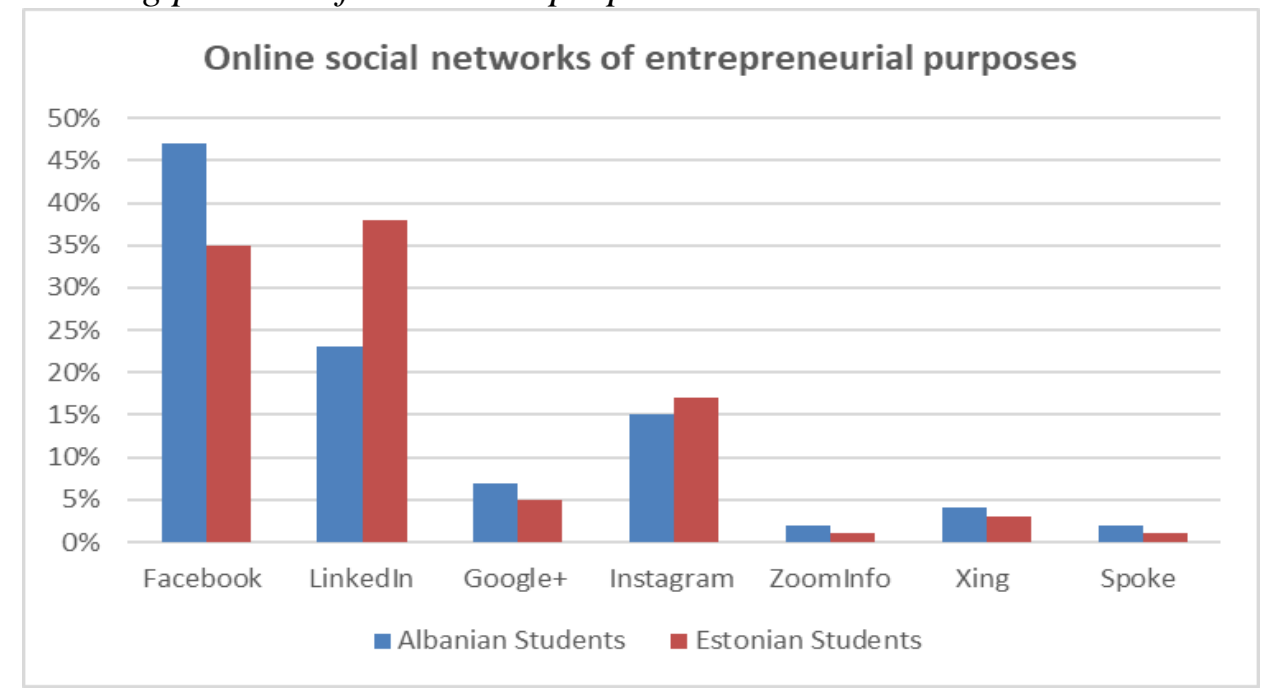

Fig 1. Comparison between Albanian and Estonian Students

47\% Students in Albania prefer using Facebook for entrepreneurial purposes, 38\% Estonian students prefer LinkedIn. This is due to the notoriety of LinkedIn as online social network in Albania. Instagram is it is becoming a relevant online social network used for en- 
trepreneurial purposes in both countries respectively for $15 \%$ of Albanian students and $17 \%$ of Estonian students. Instagram as online social network offers the possibility not just to visualize experience in online social network but it is becoming a network where online ties can become effective for business purposes. Students in both countries tend to not prefer other online social networks for entrepreneurial purposes.

Entrepreneurial learning in online social networks (Facebook vs LinkedIn).

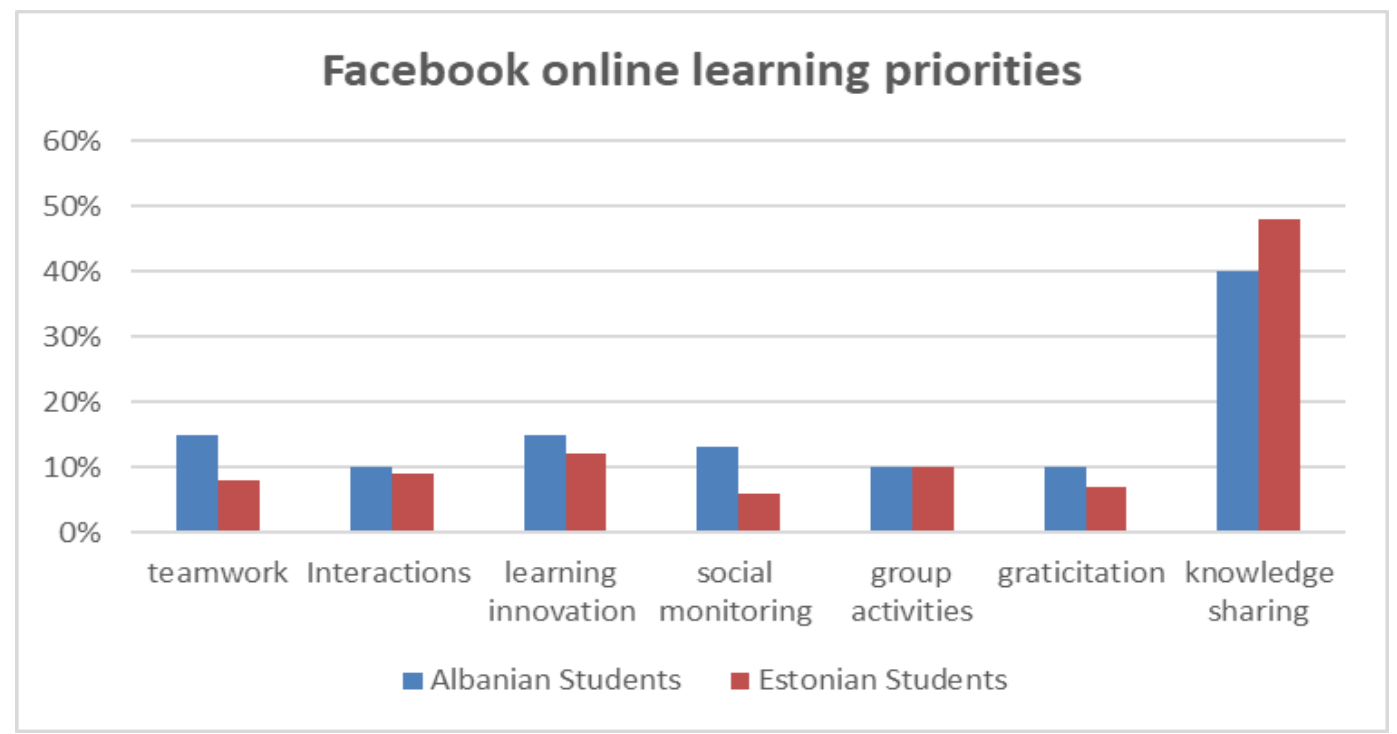

Fig 2. Facebook online learning priorities comparison

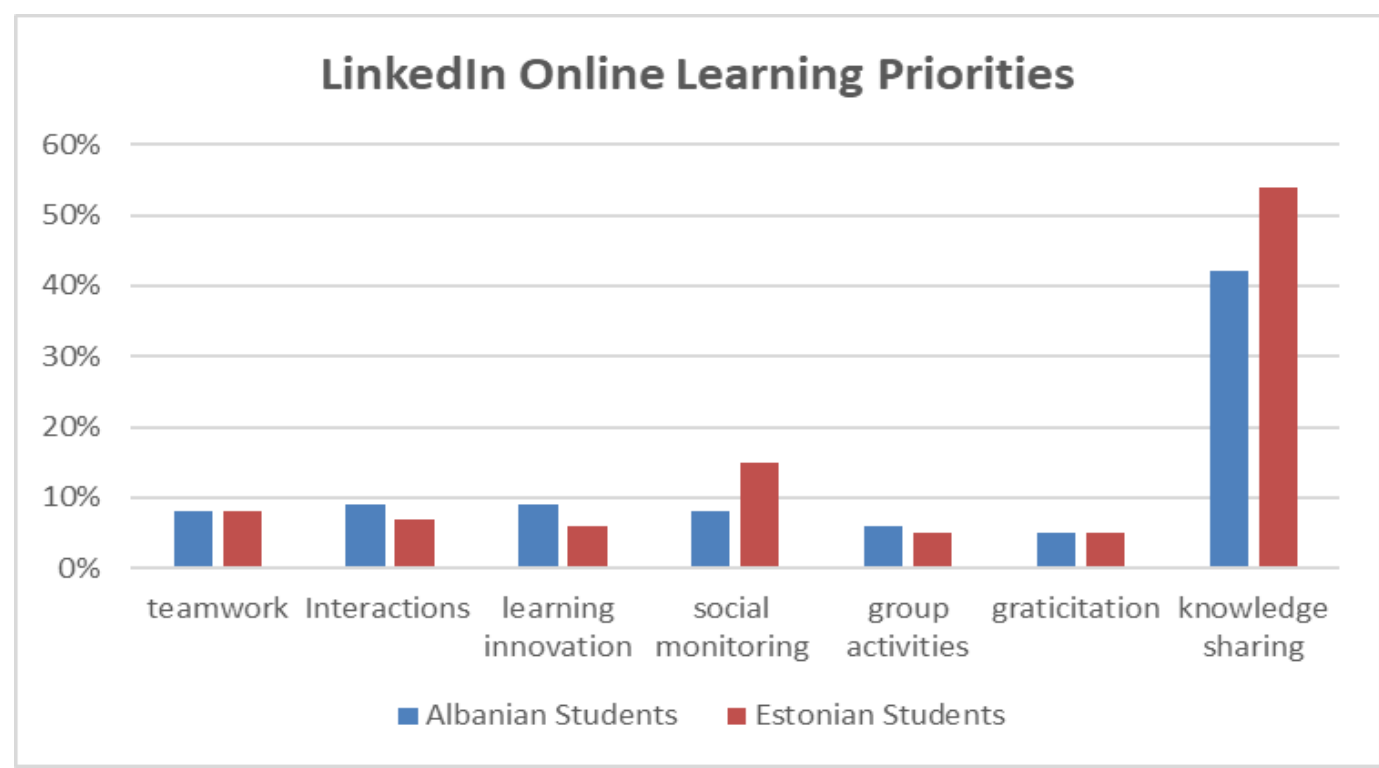

Fig 3. LinkedIn Online Learning Priorities Comparison

Knowledge sharing is the main reason that facilitates learning process in Facebook and in LinkedIn I both countries although $52 \%$ students in Estonia prefer to share knowledge through LinkedIn. Social monitoring is more effective in Facebook as learning priority for
$13 \%$ of Albanian students and for $16 \%$ of Estonian Students is more effective in Facebook. Teamwork is more relevant in Facebook as a learning priority for Albanian students compared to Estonian students; this can be due to the informal perception of the configuration of 
this online social network. Learning innovation is more relevant in Facebook for students in both countries. Interaction is more important in Facebook compared to LinkedIn for Estonian students, for Albania student interaction, as entrepreneurial learning priority is the same in Facebook and LinkedIn. Group activities are more important in Facebook for students in both countries with $10 \%$ respectively. Gratification is more important in Facebook for students in Albania with 10\%, for students in Estonia there is no difference between Facebook and LinkedIn.

Overall, from the survey, in both countries, students do not make a significant difference between online and offline ties for entrepreneurial opportunity recognition in online social networks, for starting a new entrepreneurial project or for sharing business ideas. Online social networking preferences for entrepreneurial purposes in both countries are dominated by Facebook and LinkedIn followed up by Instagram.

As learning priorities, they focus in knowledge sharing process, teamwork, social monitoring and interaction in Facebook and LinkedIn that are connected to online ties. In focus group and blog analysis is explored further how online ties can be explored further for entrepreneurial learning purposes in online social networks and how differently young students can strategically learn through online social ties compared to face-to-face ties and how these ties can affect entrepreneurial culture.

\subsection{Comparing focus groups and blog anal- ysis results}

Four main themes were identified after encoding process.

\section{Cross boarder opportunities from online ties}

Participants of the focus groups did not make any distinction between online and offline ties for entrepreneurial opportunities as a participant would mention

"...it is true that at the end of the day the interaction is virtual but what you get from the network after all is real, if there is something interesting to discuss about entrepreneurial projects than why not..."

Although participants in the focus group assume that in Albania we prefer face-to-face contact traditionally but due to the specific business environment of the country that is small economy still in transition young students would rely to also to entrepreneurial opportunities that come from online ties. One participant took as an example that many of the events where he participated with his business idea were found by him through Facebook rather than from his daily interaction with his face-to-face ties.

Online ties cannot be categorized as online social ties within the context of online social networks for the young student but those ties in the context of entrepreneurial learning can be defined as online entrepreneurial ties, which are a complement to face-to-face entrepreneurial ties.

\section{Facebook learning vs LinkedIn learning}

"...you can get the information you need everywhere, but yet depends on the network and on how well you know the network..."

Participants in the focus group admitted that online social networks are overloaded with information, yet it is important in the process of entrepreneurial learning to asses entrepreneurial knowledge learning priorities before you undertake the learning process. It is easy and costless to share knowledge in online social network but it is important to make an assessment of entrepreneurial knowledge expertize in online social networking. ".. it is about to know what do you know already and what do you what to need to know from the network, and if there is any kind of expert in the network..." . For some kind of knowledge about certain business ideas or when there is the prestart phase of the entrepreneurial project $\mathrm{Fa}$ cebook is better, a simple status update is very useful, to get more formalized knowledge and expertise LinkedIn is more useful, it is like a business card network. Yet for those young people who are more involved into e-commerce or visual project, Instagram is more 
useful. Online entrepreneurial ties are useful in any case

\section{Online entrepreneurial learning strategies}

“... learning in online social networks means that you cannot be egoist and you are not alone" commented one of the participants. Online social networks facilitate distant virtual collaboration. Entrepreneurial strategic learning means learning efficiently (costless and in real-time) for young students and effectively (when it is needed). Although there is a distinction between being a constant entrepreneurial learner in online social networks through permanently and collaboratively eparticipating and sharing entrepreneurial knowledge in online social networks and relying constantly in online entrepreneurial ties or casual entrepreneurial learner in online social networks who takes advantage of learning through online entrepreneurial ties according to environment and opportunities.

\section{Online collaborative culture}

Online entrepreneurial learning is perceived as a complement to traditional entrepreneurial learning in higher education institutions. There is a lack of entrepreneurial culture in Albania, this is due to structural problems caused by transition by as well for participants it is matter of national culture that traditionally is not oriented towards entrepreneurship. Although establishing an entrepreneurial culture is, feasible and entrepreneurial, learning and transferring best practices can make this process possible. Accordingly, participants agree that online learning and international online entrepreneurial ties and entrepreneurial collaborative orientation can influence positively the establishment of such entrepreneurial culture.

\section{Comparing results from interviews}

Furthermore, survey results and focus groups results showed that the most used online social networks to further develop business ties were Facebook and LinkedIn. LinkedIn is a shadow network for young students in Albania, whereas young students in Estonia are more familiar with it. Distinctions can be made between the young student Facebook entrepreneurial tie and the young student LinkedIn entrepreneurial tie. As explored in interviews Facebook entrepreneurial tie can be born and build in an online context without previous face-to-face contact though different features of this online networks such as "friends of friends", "friends suggestions", "Facebook thematic groups" or "Facebook thematic pages" or "Facebook events", although such features as "closed Facebook groups" are perceived to create more closed entrepreneurial communities and entrepreneurial learning perspective as knowledge is available only for the group members. Facebook entrepreneurial ties allow access not only to professional but as well to personal information of the young student user, the personal feature of the Facebook entrepreneurial ties it is important for young students in Albania as well some young students whom already have an established entrepreneurial project prefer to monitor Facebook profiles for finding business partners and hiring. Young students in Albania and in Estonia perceive the Facebook as informal entrepreneurial tie that can be useful especially share knowledge and learn about entrepreneurial opportunities especially in the pre-start or start phase of the entrepreneurial project. Monitoring Facebook ties implies access to knowledge and opportunities although young students empathize that scrolling down a newsfeed must not be sufficient, young student should carefully whom to follow and monitor depending on the nature the entrepreneurial project. Facebook entrepreneurial are alimented through features of instantaneous communication as showed in focus groups in Albania such as Facebook Messenger or Facebook Messenger for business. Tie hunting for entrepreneurial knowledge and opportunities as showed in the focus groups depends on the online learning strategy of the young students, online strategic learners would focus more on constant use Facebook for entrepreneurial purposes whereas online casual learners would tend typically to scroll the news feed. Collaborative ties would be beneficial for entrepreneurial learning pro- 
cess, in the interviews was showed that in thematic groups there might exist such a concept as online group tie, group ties tend to strengthen over and to offer a sense of belonging.

As shown in interviews LinkedIn tie is perceived as formal tie as he online network itself as professional mindset, young students would consider it as business card or CV. In Albania the network is not very popular among young students compared to Estonia, although more experienced young entrepreneurs as showed in the interviews tend to use it. Limited access to search contact service and to limit Inmail messages if you are not amongst features that limit entrepreneurial tie hunting, added costs of premium service are a barrier especially for a young student in Albania that is the process of tie hunting. Anyways as shown by focus groups and interviews such features as skills endorsement and the possibility to business write articles accommodates entrepreneurial opportunities that come from LinkedIn.

\section{Discussion and conclusions}

As showed by survey results, focus groups content analysis of posts in the course blog Business in Virtual Networks results interviews with more experienced young entrepreneurs online ties established in online social networks that may include entrepreneurial ties established in an offline context and entrepreneurial ties established virtually within the context of online social networks are connected to online entrepreneurial learning, entrepreneurial knowledge sharing and crossborder entrepreneurial opportunities. Young students in Albania and in Estonia did not show an entrepreneurial tie preference between online and offline when it comes to entrepreneurial learning and cross-border business opportunities. Online and offline entrepreneurial ties are not exclusive but mutually complementary, young students rely equally on online and offline entrepreneurial ties. A young student even in the context of small open transition economy can rely on online ties offered by Facebook and LinkedIn with no difference between online and offline ties, there are not remarkable differences compared to the Estonian context where LinkedIn tie is more common compared to Albania due to the popularity of the online network in the country.

Attention should be drawn on how to develop Facebook tie, LinkedIn and Facebook tie these concepts can be further integrated in networking theory.

\section{References}

[1] Venesaar, U., Mets, T., Paes, K., Elenurm, T., Masso, J., Küttim, M. \& Konsa, P. Globaalne ettevõtlusmonitooring 2013. Eesti Raport (Global Entrepreneurship Monitor 2013. Estonian Report), Tallinn: Estonian Development Fund, 2014.

[2] Aldrich, H. \& Zimmer, C. "Entrepreneurship through social networks." In Sexton $\mathrm{D} \&$ Smilor R (eds) The Art and Science of Entrepreneurship, 3-23. Cambridge, Mass: Ballinger, 1986

[3] Hoang, H., and Antoncic, B. "Networkbased research in entrepreneurship: A critical review," Journal of Business Venturing, 18(2), 2003, pp.165-187.

[4] Granovetter, Mark.S., "The Strength of Weak Ties," American Journal of Sociology 78(6), 1973, pp. 1360-1380.

[5] Dubini, P., \& Aldrich, H., "Personal and Extended Networks are Central to the Entrepreneurial Process," Journal of Business Venturing, 6, 1991, pp. 305-13.

[6] Granovetter, M., "The Strength of Weak Ties: A Network Theory Revisited," Sociological Theory. 1, 1983, pp. 201-330.

[7] Aral, S. , "The future of weak ties," American Journal of Sociology, 121(6), 2016, pp. 1931-1939.

[8] Doerfel, M.L., and Moore, P.J., "Digitizing Strength of Weak Ties: Understanding Social Network Relationships through Online Discourse Analysi," Annals of the International Communication Association, 40(1), 2016, pp. 127-148.

[9] Nahapiet, J. and Ghoshal, S., "Social Capital, Intellectual Capital, and the Organizational Advantage," Academy of Management Review, 23(2), 1998, pp. 242-66.

[10] Larson, A., \& Starr, J. A., “A network 
model of organization formation," Entrepreneurship: Theory and Practice, 17(2), 1993, pp. 5-15.

[11] Venkataraman, S., and Sarasvathy, S.D., Strategy and entrepreneurship: outlines of an untold story. In: Hitt, M.A., 2001

[12] Hansen, M. T., "The search-transfer problem: The role of weak ties in sharing knowledge across organization subunits," Administrative Science Quarterly, 44, 1999, pp. 82-111.

[13] Eagle, N., Macy, M., Claxton, R., "Network diversity and economic development," Science, 328, 2010, pp. 1029-1031

[14] Phua, J., Jin, S.V. and Kim, J.J., "Uses and gratifications of social networking sites for bridging and bonding social capital: A comparison of Facebook, Twitter, Instagram, and Snapchat," Computers in Human Behavior, 72, 2017, pp. 115-122.

[15] Hampton, K., Sessions Goulet, L., Rainie, L., and Purcell, K., "Social networking sites and our lives," Washington, DC: Pew Internet and American Life Project, 2011.

[16] Panovich, K., Miller, R., and Karger, D., "Tie Strength in Question \& Answer on Social Network Sites," In Proc. CSCW, 2012, pp. 1057-1066.

[17] Ipe, M., "Knowledge sharing on organizations: A conceptual framework," $\mathrm{Hu}-$ man Resource Development Review, 2(4), 2003, pp. 337-359.

[18] Hansen, M. T., The search-of weak ties in sharing knowledge across organization subunits. Administrative Science Quarterly, 44, 1999, pp. 82-111.

[19] Van Wijk, R., Jansen, J. P. and Lyles, M. A. "Inter- and intra-organizational knowledge transfer: a meta-analytic review and assessment of its antecedents and consequences," Journal of Management Studies, 45, 2008, pp. 815-38.

[20] Cummings, J. N., "Work groups, structural diversity, and knowledge sharing in a global organization," Management Science, 50(3), 2004, pp. 352-364.

[21] Bowley, R. C. A comparative case study: Examining the organizational use of social networking sites, Thesis, The University of Waikato, Hamilton, 2009

[22] Postman J., SocialCorp. Social Media Goes Corporate. New Riders, Berkeley, USA, 2009.

[23] Elenurm, T., Ennulo, J., and Laar, J., Structures of motivation and entrepreneurial orientation in students as the basis for differentiated approaches in developing human resources for future business initiatives. EBS Review, (23), 2007.

[24] Aral, S., Dellarocas, C., and Godets, D., "Introduction to the Special Issue-Social Media and Business Transformation: A Framework for Research," Information Systems Research, 2013, pp. 3-13.

[25] Kane, G.C., and Fichman, R.G., "The shoemaker's children: using wikis for information systems teaching, research, and publication," MIS Quart. 33 (1), 2009, pp. $1-17$.

[26] Joy, S., \& Kolb, D. A., "Are there cultural differences in learning style?," International Journal of Intercultural Relations, 33(1), 2009, pp. 69-85.

[27] Hofstede, G., Culture's Consequences: Comparing Values, Behaviors, Institutions and Organizations across Nations. Thousand Oaks, CA: Sage (co-published in the PRC as Vol. 10 in the Shanghai Foreign Language Education Press SFLEP Intercultural Communication Reference Series, 2008)

[28] Smith M., Gallagher M., Wosu H., Stewart J., Cree V. E., Hunter S., Evans S., Montgomery C., Holiday S., Wilkinson $\mathrm{H}$. "Engaging with involuntary service users in social work: Findings from a knowledge exchange project," British Journal of Social Work , 42(8), 2012, pp. 1460-77 


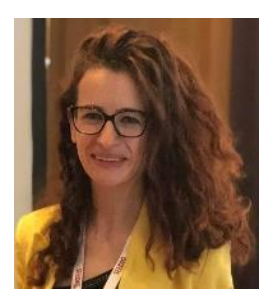

Oliana SULA is a doctoral student at Estonian Business School, Tallinn, Estonia and a lecturer and researcher at Department of Management, Faculty of Business, University" Aleksander Moisiu" Durres, Albania. Her research focuses in online social networks, youth entrepreneurship, online networking competencies, digital competencies and Internet governance. She has published several research articles and she participated in several scientific conferences. She is engaged in regional, European and global initiatives on digital literacy and internet governance.

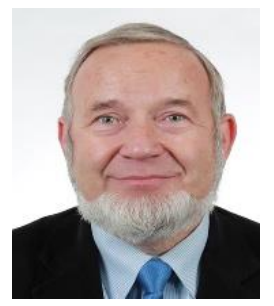

Tiit Elenurm is professor at the Department of Management at the Estonian Business School. Ph. D. in 1980 for the dissertation "Management of the Process of Implementation of New Organizational Structures". Author of more than 120 research publications. Research interests include knowledge management, innovative entrepreneurship and international transfer of management knowledge. 